\title{
Increasing the Prediction Efficiency of Hansen Solubility Parameters in Supercritical Fluids
}

\author{
Csaba Dezső András ${ }^{1,2 *}$, László Mátyás³, Botond Ráduly³, Rozália Veronika Salamon \\ 1 Department of Food Science, Faculty of Economics, Socio-Human Sciences and Engineering, Miercurea Ciuc, \\ Sapientia Hungarian University of Transylvania, R-530104 Miercurea Ciuc, Libertății sq. 1, Romania \\ 2 Department of Chemical and Environmental Process Engineering, Faculty of Chemical Technology and Biotechnology, \\ Budapest University of Technology and Economics, H-1111 Budapest, Budafoki út 8/F2, Hungary \\ ${ }^{3}$ Department of Bioengeneering, Faculty of Economics, Socio-Human Sciences and Engineering, Miercurea Ciuc, \\ Sapientia Hungarian University of Transylvania, R-530104 Miercurea Ciuc, Libertății sq 1, Romania \\ *Corresponding author, e-mail: andrascsaba@uni.sapientia.ro
}

Received: 01 July 2018, Accepted: 14 December 2018, Published online: 18 March 2019

\begin{abstract}
This work describes a simplified method developed for calculating the Hansen parameters (HSPs) for scCO $\mathrm{CO}_{2}$-polar modifier solvent mixtures. The method consists in fitting $2^{\text {nd }}$ order equations on the calculated values of HSPs of pure components in function of pressure and temperature. It has been proved that these equations are suitable for the characterization of the above system. The current work also proposes a modified representation method, which eliminates the shortcomings of the original ternary Teas diagram, normally used for the representation of the Hansen parameters. On the one hand, the Teas diagram uses quantities without any physical meaning and, on the other hand, the illustration of the solubility information is distorted because it does not take into account the differences of the Hildebrand parameters of different solvents. The factors we have chosen to represent on the ternary diagram possess physical meaning (cohesion energy density partitions). The distortion was eliminated by extending the Teas diagram to a prismatic three dimensional representation. We proved that the Hansen-ellipsoid from the Cartesian coordinate system $\left(d_{d}=f\right.$ $\left.\left(\delta_{H}, d_{p}\right)\right)$ is transformed in an ellipsoid also in the new coordinate system (the transformation is pseudo-isomorphic). Nonetheless, the suggested corrections improve the accuracy of the Hansen method, in some cases the interactions between the solvents and the dissolved materials are still not predicted with sufficient accuracy. Most probably a thermodynamic-based correction of the values of the HSPs of small molecules could lead to a significant improvement of the predictive ability of the newly developed method.
\end{abstract}

Keywords

Hansen solubility parameters, supercritical fluids, co-solvents, carbon dioxide, ethanol

\section{Introduction}

The application of supercritical fluid state (SCF) solvents is widening as there is an increasing demand for green chemical technologies and analytical procedures (extraction, solid particle formulation, chromatography). Compared to conventional solvents, in the supercritical state the transport properties improve (by increasing the diffusion coefficient and the decreasing viscosity) by an order of magnitude.

The most commonly used supercritical fluid solvent is the carbon dioxide $\left(\mathrm{scCO}_{2}\right)$, which is used on large industrial scale for the extraction of bioactive plant ingredients. In addition to its environmental-friendly properties, the biggest advantage of the supercritical fluid carbon dioxide is the tunability of the solvent. The variation of solubility with the operating parameters (pressure and temperature) enables the shifting of the selectivity of the extraction process. This is directly correlated with density, or indirectly with other density-dependent physical properties (e.g. relative permittivity). The $\mathrm{scCO}_{2}$ is a non-polar solvent, therefore it is less suitable for dissolving polar compounds; for this purpose the addition of polar modifier is needed. Despite it is nonpolar, it is polarizable, and possesses hydrogen bond forming ability as acceptor. Its interaction with other compounds is complex, not only the dispersion forces are important. For this reason, the Hildebrand description of its interactions is not sufficient and Hansen solubility 
parameters are needed to deal with its interactions beyond those due to the dispersion forces [1].

In the case of solvent mixtures, the polar modifier concentration is a new parameter to adjust the desired solubility. The use of supercritical solvents allows the gentle removal of bioactive components in plant materials [2].

It is important to know the critical properties of the solvent mixtures because one can count on the intensive material transfer (low viscosity, high diffusion factor only close to the critical point). In the same time the co-solvent should easily be removable after the extract is dissolved. Therefore, the amount of polar modifier that can be used in practice is about $2-20 \mathrm{~mol} \%$. In the case of supercritical extraction, the co-solvent is almost exclusively ethanol, while in chromatography it may be much more varied.

To quantify the solubility, the square root of the volume cohesion energy is used, also called the Hildebrand parameter $(\delta)$. However, in many cases it does not adequately characterize the solubility. Hansen parameters $\left(\delta_{\text {dispersion }}, \delta_{\text {polar }}, \delta_{\mathrm{H}-\text { bond }}\right)$ characterize better the physical interactions between solutes and solvents. These parameters are density-dependent, i.e. in case of change of pressure and temperature, especially in the near-supercritical domain the changes are more accentuate.

When the points of the solute and the solvent are sufficiently close in Hansen space, the fluid solvates the compound.

The aim of the work is to show new possibilities for increasing the prediction efficiency of the Hansen parameters (HSPs) in different supercritical processes. We developed a relatively simple short-cut method for the calculus of solvent mixtures in supercritical state, and invented also, a new family of 3D representation method, which will be able to enhance the understanding of the process parameters on solubility variation during these processes.

\section{Theoretical background}

The efficiency of solid-fluid extraction of the solubility theory has been proven for plant compound extraction, using water, ethanol or mixtures of them [3]. The solubility of the solvent is characterized by the Hildebrand parameter. This formalism of solubility has been extended for supercritical fluids [4]. This extension is important because the supercritical fluids are tunable solvents: by changing their parameters (pressure, temperature), many other properties (density, viscosity, diffusion coefficient) will change, and also their solubility changes, important from the point of view of the extraction. To describe these changes one can use the Giddings equation, which extends the Hildelbrand relation to supercritical state $[5,6]$. The total cohesion energy is composed of three types of energies coming from three interactions:

$E=E_{d}+E_{p}+E_{H}$

where : $E_{d}, E_{p}$ and $E_{\mathrm{H}}$ are the dispersion, polar interaction, and the hydrogen bond energy, respectively.

Dividing the Eq. (1) with the molar volume $\left(V_{m}\right)$, one finds the square of correspondig solubility parameters (Eq. (2)), resulting the HSPs, $\delta_{d}, \delta_{p}$ and $\delta_{H}$ (Eq. (3)), and the Hildebrand parameter, $\delta$.

$\delta^{2}=E / V_{m}$,

$\delta^{2}=\delta_{d}^{2}+\delta_{p}^{2}+\delta_{H}^{2}$

It has been shown that for supercritical fluid extraction processes the solvent density is an important factor $[4,7,8]$. The HSPs of $\mathrm{scCO}_{2}$ (and of solvents in general) can be evaluated only by knowing the density (or molar volumes) [9]. A practical method for the determination of experimental values of the solubility parameters for macromolecules [10, 11], and even for small molecules [12] is the inverse gas chromatography (IGC). The results in some cases are different from theoretical values [12], therefore it is important to improve the calculation methods.

Although the carbon dioxide is a very good solvent having multiple advantages, it has a limited range when one arrives to dissolve polar components. This limitation comes from the fact that the values of the polar and hydrogen-bond components of HSPs of the $\mathrm{scCO}_{2}$ are relatively low. To extend the solubility of $\mathrm{scCO}_{2}$ for polar substances, polar co-solvents have been added. In most cases this co-solvent is the ethanol, because it is considered GRAS (Generaly Regarded As Safe).

The amount of ethanol that can be added is limited by two factors. On the one hand there is a shift of the critical point to higher temperatures for increasing ethanol concentration [13]. On the other hand, once a larger amount of ethanol is used, it cannot be separated from the product just by lowering the pressure. By this an important feature of the supercritical extraction may be lost. In our study we investigated the range of 0-0.2 mole fraction of polar modifier.

The calculation of the Hansen parameter values for $\mathrm{scCO}_{2}$-ethanol mixtures has been made previously $[14,15]$ and was used in practice recently [16]. It is clear, that not all aspects are explained only by solubility, for example 
the solute Antoine constants have an important effect in extraction processes [16]. It is important to mention, that the exact solubility values for different substances may not be predicted by the Hansen method, only a fuzzylike (as good solvent or not) prediction is possible. At the moment the exact solubility values can be predicted only by Chrastil-like semi-empirical models [17].

The Hansen plot is the graphical representation of the function $\delta_{d}=f\left(\delta_{H}, \delta_{p}\right)$. For a liquid solvent, this is a point. A supercritical solvent representation in the Hansen space is not a point, but a surface (in function of pressure and temperature); in case of supercritical solvent mixtures this degenerates in a spatial zone ("cloud"). The Teas chart has been introduced as an alternative to the spatial Hansenplot. Here the individual Hansen parameters are normalized by the sum of the three parameters [18], resulting in quantities that may be considered fractional solubility parameters, without real physical meaning. The representation is in a planar, ternary coordinate system. The main issue with this chart is its intrinsic distortion of distances, given by the false assumption that the value of the Hildebrand parameter $(\delta)$ is the same for all substances [19]. The partial cohesion energy densities concept has been introduced [20] to remove this major inconvenient, but for some unknown reason it has not become widespread [21]. The Teas partial HSPs are given by Eq. (4), the partial cohesion energy densities (PCED) by Eq. (5). The difference between the two set of factors might seem small, but enough to eliminate this major drawback of the Teas chart (distorsion)

$$
\begin{gathered}
g_{i}=\frac{\delta_{i}}{\sum_{i=1}^{3} \delta_{i}}, \\
f_{i}=\frac{\delta_{i}^{2}}{\sum_{i=1}^{3} \delta_{i}^{2}} .
\end{gathered}
$$

\section{Calculation methods}

The values of the HSPs in supercritical state were obtained [22] by Eqs. (6)-(8)

$$
\begin{aligned}
& \delta_{d}=\delta_{d, r e f}\left(\frac{V_{r e f}}{V}\right)^{1.25}, \\
& \delta_{p}=\delta_{p, r e f}\left(\frac{V_{r e f}}{V}\right)^{0.5}, \\
& \delta_{h}=\delta_{h, r e f} \cdot \exp \left[1.32 \cdot 10^{-3}\left(T_{r e f}-T\right)+\ln \left(\frac{V_{r e f}}{V}\right)^{0.5}\right] .
\end{aligned}
$$

The reference values for HSPs $\left(d_{r e f}\right)$ temperatures $\left(T_{r e f}\right)$ and molar volumes $\left(T_{r e f}\right)$ were obtained from Professor Hansen's reference work [23]. The densities of $\mathrm{scCO}_{2}$ and ethanol, however, were not calculated from the equation of state (EoS) as previously [22, 23], but measured values were used [24, 25]. The adopted method for HSPs calculation for solvents in sub-and supercritical state is widely accepted, and is considered to give exact values even for the Hildebrand parameters [9]. All the calculi and graphic representations have been done in Statistica 8.0 software environment (Statsoft, Inc.). On the calculated data points a quadratic two-variables (pressure and temperature) polynomial equations were fitted (Eq. (9)), both for ethanol and carbon dioxide:

$\delta_{j, i}=a_{j, i}+b_{j, i} T+c_{j, i} p+d_{j, i} T^{2}+e_{j, i} p T+f_{j, i} p^{2}$

where: $a, f$ are the fitting coefficients; the index $i$ denotes the components (ethanol or $\mathrm{CO}_{2}$ ), the index $j$ denotes the type of the solubility parameter (indices $d, p$ or $H$ for Hansen, missing index for Hildebrand parameter).

The Hansen parameters for mixtures were calculated from the Hansen parameters of the individual components. For HSPs of solvent mixtures the volumetric fraction-weighted average of the components HSPs are used (Eq. (10))

$\delta_{j, \text { mix }}=\sum_{i=1}^{n} \Phi_{i} \delta_{j, i}$.

Where: $\Phi_{i}$ is the volumetric fraction of component $i$. This is the equation of HSPs for solvent mixtures, where $n$ is the number of components of the mixture, and $j$ is the index denoting the different solubility parameters as follows: $j=d, p, H$ - dispersion, polar and hydrogen bond partial HSP; missing - Hildebrand parameter.

\section{Results}

\section{1 The fitting of the HSPs polynomials}

The results of the fit for Hildebrand parameter for $\mathrm{CO}_{2}$ and ethanol are shown on Fig. 1. In the coordinate system $(T, p, \delta)$ we get a smooth surface.

The values of the fitted parameters of Eq. (4) for ethanol and carbon-dioxide (for both, Hildebrand and Hansen parameters) are shown in Table 1.

As generally the Hansen parameters are given with one-decimal precision $[1,3]$, therefore the temperature square coefficients should be given up to the fifth digit to compensate the relative high value of the temperature range. To maintain the unitary feature of the description all the coefficients (in the Table 1) are rounded to the fifth digit. 


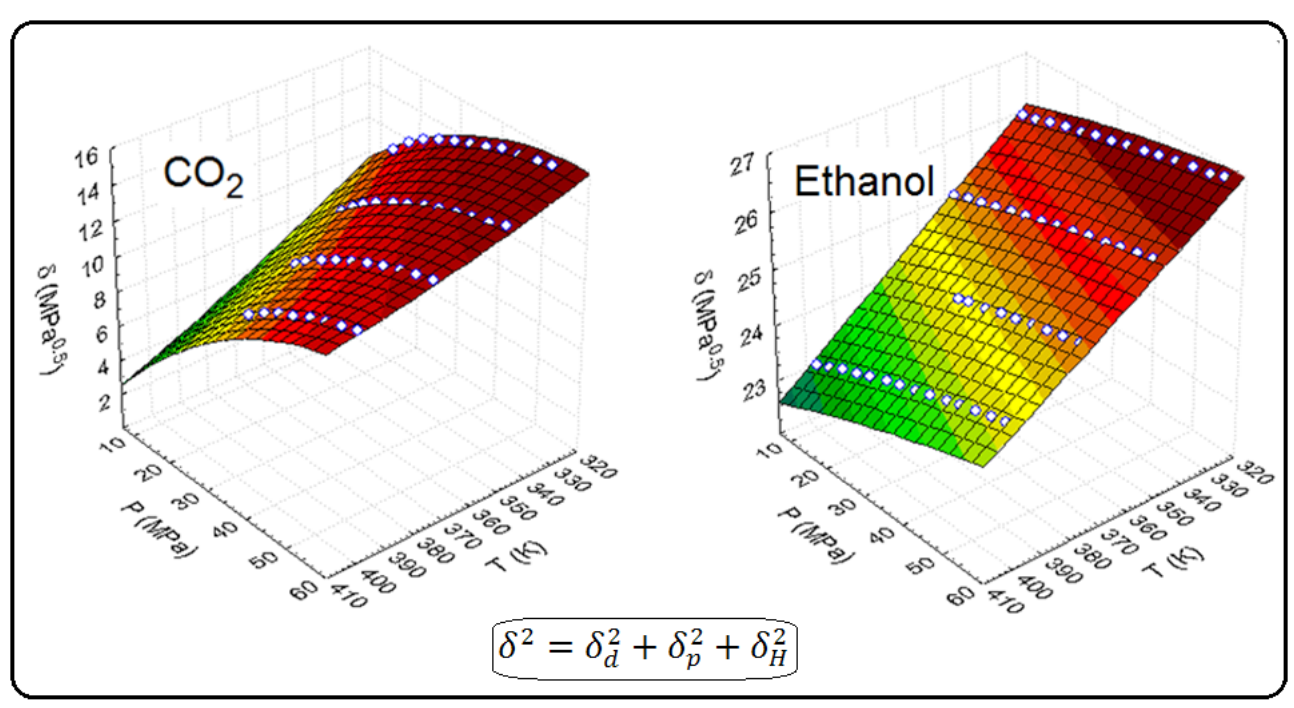

Fig. 1 The Hildebrand parameter $(\delta)$ of $\mathrm{CO}_{2}$ and ethanol

Table 1 The coefficients for the Hildebrand and Hansen solubility parameters

\begin{tabular}{|c|c|c|c|c|c|c|c|}
\hline \multirow{2}{*}{ Compound } & \multirow{2}{*}{ Parameter } & \multicolumn{6}{|c|}{ Fitted coefficients } \\
\hline & & $\mathrm{a}$ & $\mathrm{b}$ & $\mathrm{c}$ & $\mathrm{d}$ & $\mathrm{e}$ & $\mathrm{f}$ \\
\hline \multirow{4}{*}{$e^{N}$} & $\delta_{d}\left(\mathrm{MPa}^{0.5}\right)$ & 52.67287 & -0.19614 & 0.01697 & 0.00015 & 0.00081 & -0.00236 \\
\hline & $\delta_{p}\left(\mathrm{MPa}^{0.5}\right)$ & 13.00137 & -0.03278 & -0.01261 & 0.00002 & 0.00023 & -0.00057 \\
\hline & $\delta_{\mathrm{H}}\left(\mathrm{MPa}^{0.5}\right)$ & 14.51502 & -0.04283 & -0.00151 & 0.00003 & 0.00017 & -0.00049 \\
\hline & $\delta\left(\mathrm{MPa}^{0.5}\right)$ & 55.04864 & -0.19630 & 0.01691 & 0.00015 & 0.00080 & -0.00232 \\
\hline \multirow{4}{*}{$\underset{\text { 㐊 }}{\stackrel{\Xi}{\Xi}}$} & $\delta_{d}\left(\mathrm{MPa}^{0.5}\right)$ & 21.01304 & -0.01209 & -0.01394 & -0.00002 & 0.00012 & -0.00011 \\
\hline & $\delta_{p}\left(\mathrm{MPa}^{0.5}\right)$ & 9.82342 & -0.00176 & -0.00442 & 0 & 0.00003 & -0.00003 \\
\hline & $\delta_{\mathrm{H}}\left(\mathrm{MPa}^{0.5}\right)$ & 31.68301 & -0.04572 & -0.00403 & 0.00002 & 0.00005 & -0.00006 \\
\hline & $\delta\left(\mathrm{MPa}^{0.5}\right)$ & 39.10087 & -0.04224 & -0.01368 & 0 & 0.00012 & -0.00011 \\
\hline
\end{tabular}

The Hansen plot of the HSPs for $\mathrm{CO}_{2}$-ethanol mixture $\left(\Phi_{\text {ethanol }} \leq 0.2\right)$ is represented in function of intrinsic process parameters (pressure and temperature) on Fig. 2. In the usual supercritical fluid extraction domain ( $p=8-60 \mathrm{MPa}$, $T=275-350 \mathrm{~K})$ the Hansen-diagram of $\mathrm{CO}_{2}$-ethanol mixture is represented on Fig. 2. As it was expected, by increasing the ethanol fraction in the mixture, both the polar $\left(\delta_{p}\right)$ and hydrogen-bond $\left(\delta_{H}\right)$ component of the mixtures Hansen parameters increase. In this domain, the hydrogen bond component increases about twice as much as the polar component for all pressure-temperature pairs.

\section{2 The representation of the HSPs in ternary 2D and 3D modified Teas chart}

In this type of representation the relative contribution of the different forces (van der Waals, polar, hydrogen bond) to the total cohesion interaction can be shown simultaneously. The first attempt was the Teas plot, but results in a distorted image, by losing important information, the value

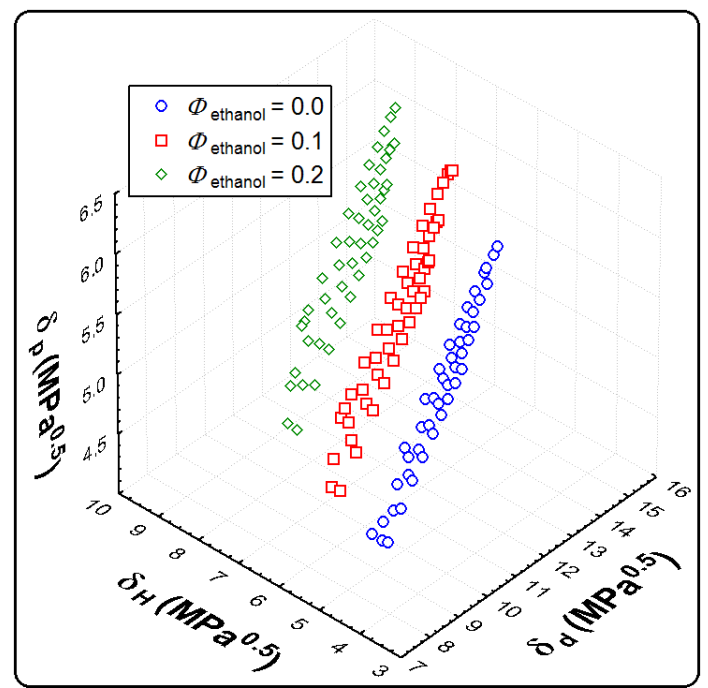

Fig. 2 The Hansen plot for $\mathrm{CO}_{2}+$ ethanol mixtures

of the Hildebrand parameter. Using the concept of the partial cohesive energy density, the distortion is remediated. For $\mathrm{scCO}_{2}$ the isothermal and the isobaric two-dimensional 
diagrams are shown on Fig. 3, illustrating mainly the variation domains of the factors. At higher temperature the variation domain of isotherms is wider (Fig. 3(a)), for isobars the same happens at low pressures (Fig. 3(b)). By taking into account an additional spatial axis, much more information can be shown (Fig. 4). For isotherms (Fig. 4(a)) the curvature shows that at higher temperatures the variation of the factors are steeper, but at high pressures the isotherms converge. The isobars are more curved at low pressures (Fig. 4(b)), although at low temperatures and high pressures the isobars converge. To be more expressive, the original ternary diagram could be extended adding various vertical axes (e.g. $p, T$ or even $\delta$ ), to obtain a set of various
3D representations (Fig. 5). On Fig. 5, the increasing trend of Hildebrand parameter with the higher ethanol fraction is clearly represented, as well as the decrease of the fraction of the dispersion component.

The representations of the Hansen sphere both in the Cartesian coordinate system, and in the 3D-extended ternary coordinate system are similar (Fig. 6), but the spheroid is transformed to a generalized ellipsoid (the transformation is pseudo-isomorphic). Hence this modified representation can be used the same way as the original (mixtures within the ellipsoid are good solvents for the solute), and has the advantage of intrinsically showing the Hildebrand iso-surfaces.

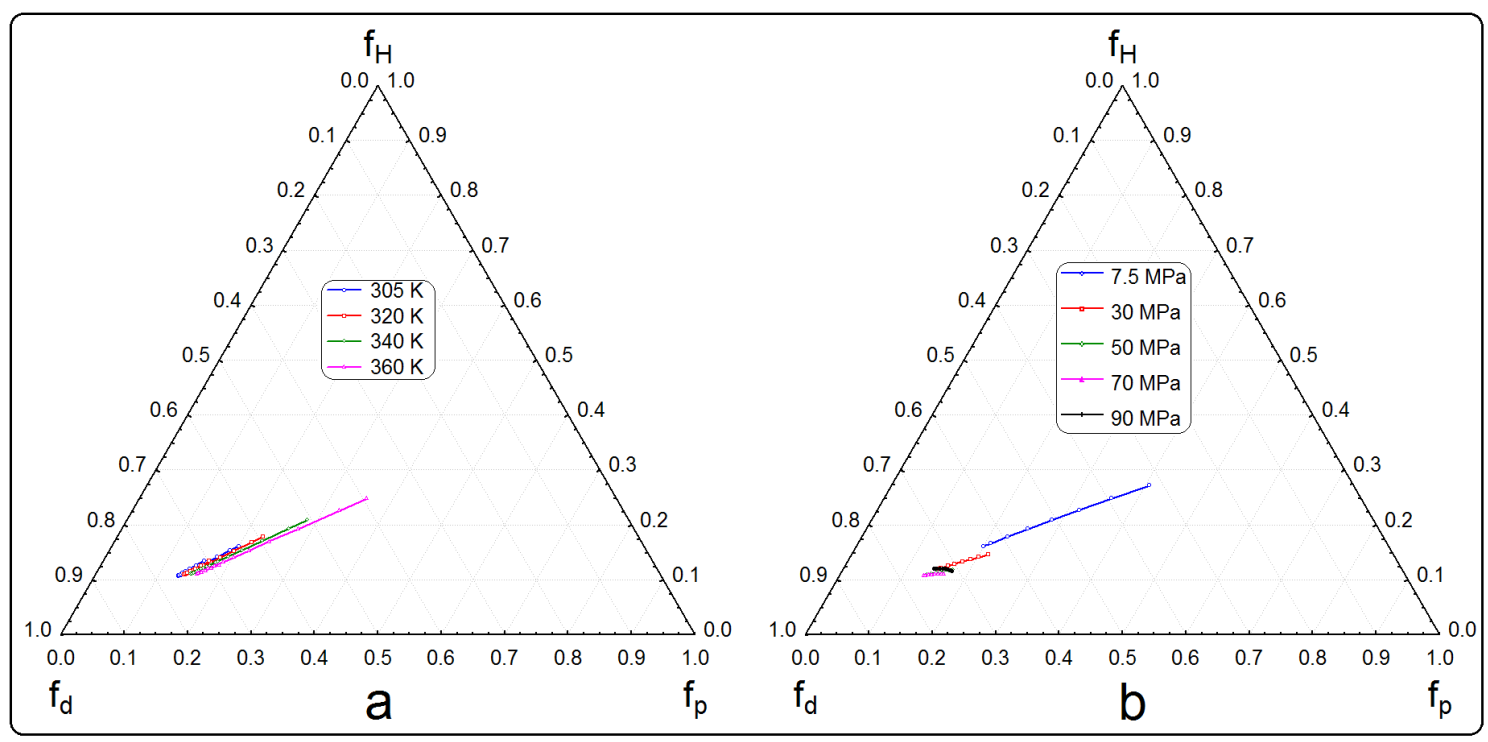

Fig. 3 The Hansen isotherms (a) and isobars (b) of $\mathrm{scCO}_{2}$ (2D ternary graphs)

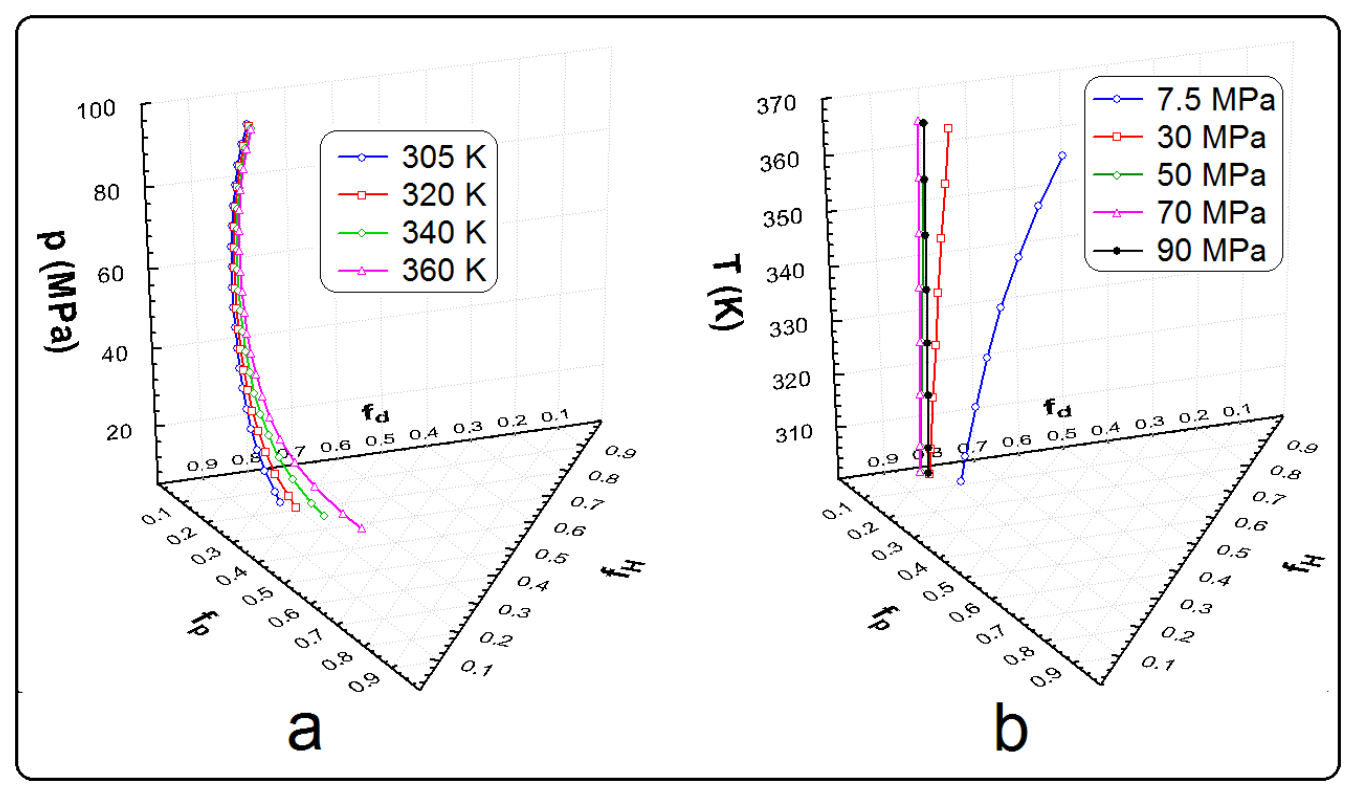

Fig. 4 The Hansen isotherms (a) and isobars (b) of $\mathrm{scCO}_{2}$ (3D ternary graphs) 


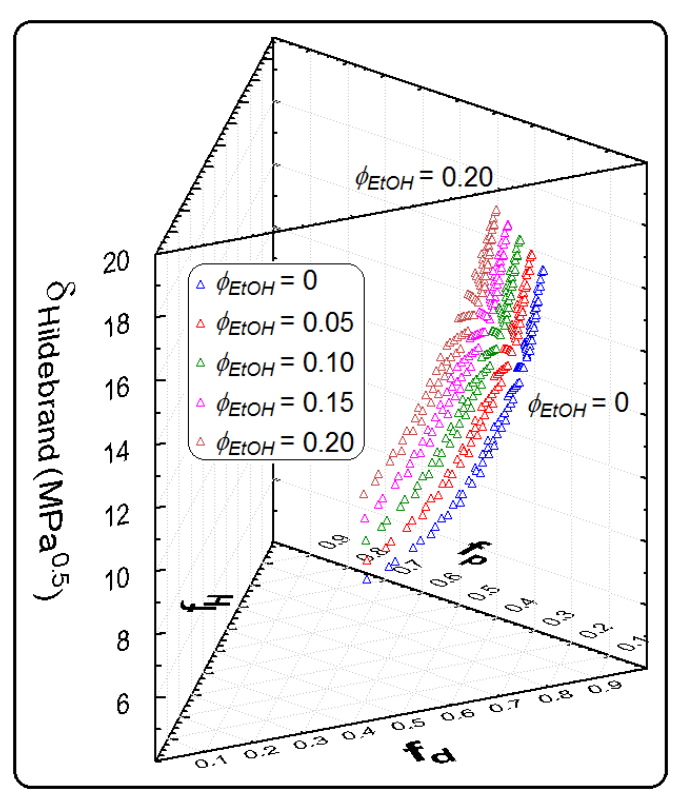

Fig. 5 The Hildebrand parameters of $\mathrm{scCO}_{2}+$ ethanol mixtures

\subsection{Further improvement possibilities of the prediction reliability of the Hansen concept}

Once the prediction of supercritical solvent mixtures HSPs is mainly solved, the HSPs values of the solutes has to be revisited. Prediction of HPSs for certain relatively complex molecules has been evaluated in a previous study by traditional group contribution method [26]. The proposed modifications are not sufficient to accurately predict the behavior of solute-solvent interactions. Therefore it is important for small solute molecules to reconsider the classic calculation of HSPs by the group contribution method, using the newly developed correction, based on thermodynamical considerations, by Louwerse and collaborators [27]. The basis for this is the presumption that when a molecule leaves the crystal structure or its own neighborhood, by dissolving in another environment, the process evolves with an entropy growth and an enthalpy loss, while a negative $\Delta G$ is maintained. Future prospects include the calculation of HSPs of different small molecules (involved in supercritical fluid extraction and chromatography, particle forming, etc.), and search of correlation between the value of the HSPs and process behavior. We are conscious about the complexity of these processes, but we hope that our work can contribute to a better understanding of different supercritical fluids systems.

\section{Conclusions}

The supercritical fluids, mainly $\mathrm{scCO}_{2}$ and their mixtures with green organic solvents (polar modifiers) are a green solvent group with great perspective. For a better description of such solvent systems an improved ternary graphs family (modified Teas plots) was developed using the partial cohesion energy density concept, the distortion of the original Teas chart was corrected, and the lost information (Hildebrand parameter) was regained. The 3D modified Teas chart could be useful for the better understanding of the dynamics of solubility variations during the SCF processes and for the design of SC solvent mixtures

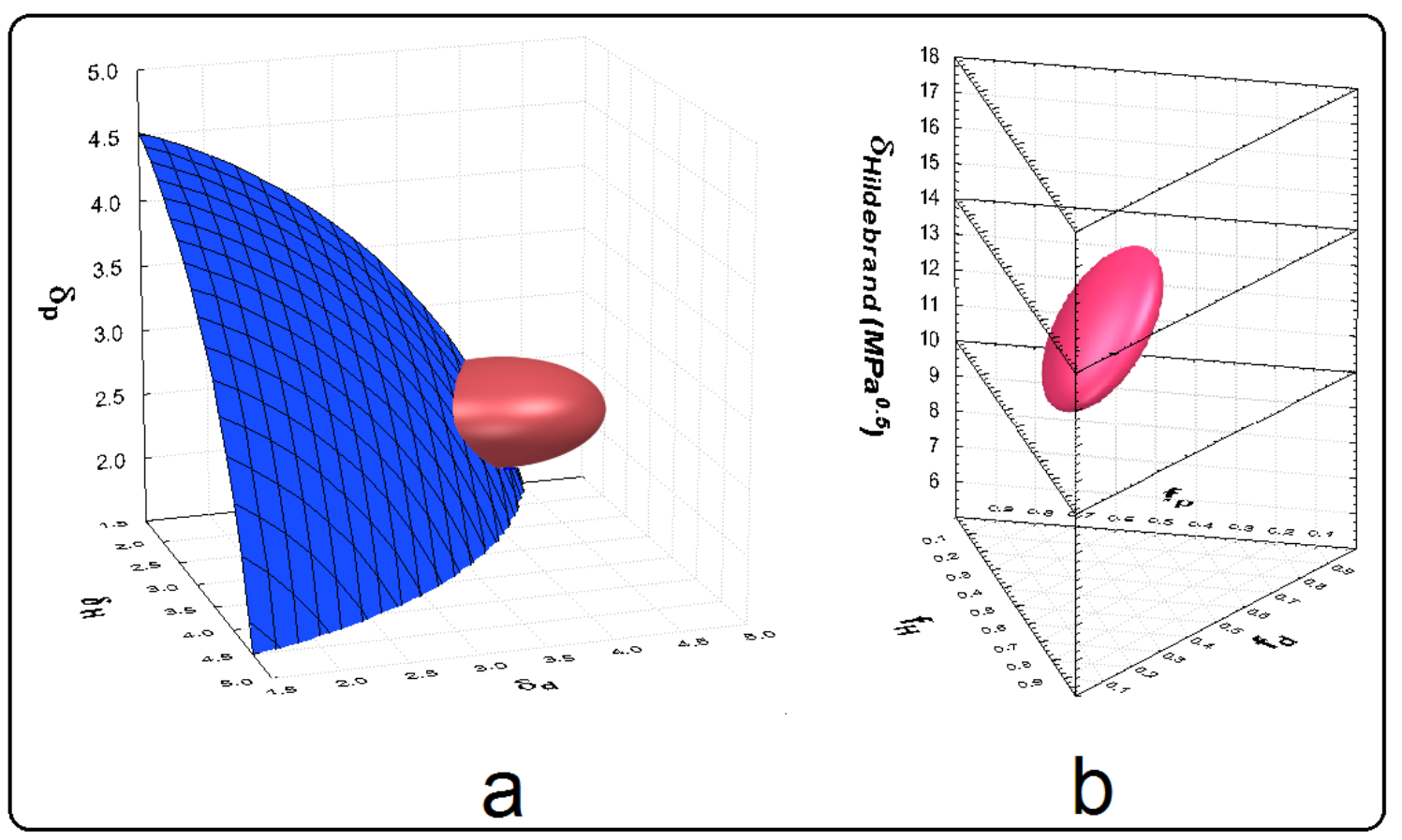

Fig. 6 The Hansen sphere in Cartesian (a) and ternary (b) coordinate systems 
for various technological processes (e.g. extraction, chiral resolution, green synthesis, cleaning, particle formation, chromatography). The Hansen-ellipsoid was translated to the new coordinate system, and it was demonstrated that the transformation is pseudo-isomorphic. In order to further tighten the gap between the model prediction and

\section{References}

[1] Marcus, Y. "Solubility Parameter of Carbon Dioxide - An Enigma", ACS Omega, 3(1), pp. 524-528, 2018.

https://doi.org/10.1021/acsomega.7b01665

[2] King, J. W. "Modern Supercritical Fluid Technology for Food Applications", Annual Review of Food Science and Technology, 5(1), pp. 215-238, 2014.

https://doi.org/10.1146/annurev-food-030713-092447

[3] Srinivas, K., King, J. W., Monrad, J. K., Howard, L. R., Hansen, C. M. "Optimization of Subcritical Fluid Extraction of Bioactive Compounds Using Hansen Solubility Parameters", Journal of Food Science, 74(6), pp. E342-E354, 2009. https://doi.org/10.1111/j.1750-3841.2009.01251.x

[4] Giddings, J. C., Myers, M. N., McLaren, L., Keller, R. A. "High Pressure Gas Chromatography of Nonvolatile Species", Science, 162(3849), pp. 67-73, 1968.

https://doi.org/10.1126/science.162.3849.67

[5] McHugh, M. A., Krukonis, V. J. "Supercritical Fluid Extraction: Principles and Practice", 2nd ed., Butterworth-Heinemann, Boston, MA, USA, 1994.

[6] Mukopadhyay, M. "Fundamentals of Supercritical Fluids and Phase Equilibria", In: Natural Extracts using Supercritical Carbon Dioxide, 1st ed., CRC Press, Boca Raton, FL, USA, 2000, pp. 65-69.

[7] Chrastil, J. "Solubility of solids and liquids in supercritical gases", The Journal of Physical Chemistry, 86(15), pp. 3016-3021, 1982. https://doi.org/10.1021/j100212a041

[8] Guigard, S. E., Stiver, W. H. "A Density-Dependent Solute Solubility Parameter for Correlating Solubilities in Supercritical Fluids", Industrial \& Engineering Chemistry Research, 37(9), pp. 3786-3792, 1998.

https://doi.org/10.1021/ie9702946

[9] Marcus, Y. "Total and partial solubility parameters of sub- and supercritical ethanol", The Journal of Chemical Thermodynamics, 126, pp. 187-189, 2018. https://doi.org/10.1016/j.jct.2018.06.023

[10] Adamska, K., Bellinghausen, R., Voelkel, A. "New procedure for the determination of Hansen solubility parameters by means of inverse gas chromatography", Journal of Chromatography A, 1195(1-2), pp. 146-149, 2008.

https://doi.org/10.1016/j.chroma.2008.05.020

[11] Kondor, A. "Determination of Hansen Solubility Parameters using Inverse Gas Chromatography", presented at $50^{\text {th }}$ Anniversary Hansen Solubility Parameters Conference, York, UK, Apr. 7, 2017.

[12] Adamska, K., Voelkel, A. "Inverse gas chromatographic determination of solubility parameters of excipients", International Journal of Pharmaceutics, 304(1-2), pp. 11-17, 2005. https://doi.org/10.1016/j.ijpharm.2005.03.040 experimental results, the HSPs of small solute molecules might be recalculated, considering thermodynamic corrections by the method proposed by Louwerse research group. These thermodynamic corrections may enable a more precise prediction of the solubility values of organic solutes in supercritical solvent mixtures.

[13] Gil, L., Blanco, S. T., Rivas, C., Laga, E., Fernández, J., Artal, M. "Experimental determination of the critical loci for $\left\{\mathrm{n}-\mathrm{C}_{6} \mathrm{H}_{14}\right.$ or $\mathrm{CO}_{2}+$ alkan-1-ol\} mixtures. Evaluation of their critical and subcritical behavior using PC-SAFT EoS", The Journal of Supercritical Fluids, 71, pp. 26-44, 2012.

https://doi.org/10.1016/j.supflu.2012.07.008

[14] András, C. D., Mátyás, L., Salamon, R. V., Szép, A. S. "A Hansen oldékonysági paraméterek szuperkritikus fluid állapotú CO2-poláris modifikátor keverékekben" (The Hansen solubility parameters for supercritical fluid $\mathrm{CO}_{2}$-polar modifier mixtures), In: Application of Supercritical Fluids Conference, Budapest, Hungary, 2015, p. 29. (in Hungarian)

[15] András, C. D., Mátyás, L., Ráduly, B., Salamon, R. V. "A novel representation method of Hansen solubility parameters for supercritical fluid solvent mixtures", presented at $50^{\text {th }}$ Anniversary Hansen Solubility Parameters Conference, York, UK, Apr. 5-7, 2017.

[16] Tirado, D. F., Tenorio, M. J., Cabañas, A., Calvo, L. "Prediction of the best cosolvents to solubilise fatty acids in supercritical $\mathrm{CO}_{2}$ using Hansen solubility theory", Chemical Engineering Science, 190, pp. 14-20, 2018.

https://doi.org/10.1016/j.ces.2018.06.017

[17] Tabernero, A., Vieira de Melo, S. A. B., Mammucari, R., Martin del Valle, E. M., Foster, N. R. "Modelling solubility of solid active principle ingredients in sc- $\mathrm{CO}_{2}$ with and without cosolvents: A comparative assessment of semiempirical models based on Chrastil's equation and its modifications", The Journal of Supercritical Fluids, 93, pp. 91-102, 2014. https://doi.org/10.1016/j.supflu.2013.11.017

[18] Hansen, C. M. "Applications - Coatings and Other Filled Polymer Systems", In: Hansen, C. M. (ed.) Hansen Solubility Parameters: A User's Handbook, 2nd ed., CRC Press, Boca Raton, FL, USA, 2007, pp. 137-149. https://doi.org/10.1201/9781420006834.ch8

[19] Durkee, J. B. " The Teas Graph (Appendix C12)", In: Cleaning with Solvents: Science and Technology, 1st ed., William Andrews-Elsevier, Oxford, UK, 2014, pp. 681-684.

[20] Vial, J. "Tridimensional representation of the solubility parameters: study of the solubilization of a vinyl chloride-vinyl acetate copolymer", Comptes Rendus de l'Académie des Sciences Serié C, 270, 3(1), pp. 683-688, 1970.

[21] Barton, A. F. M. "Solubility parameters", Chemical Reviews, 75(6), pp. 731-753, 1975.

https://doi.org/10.1021/cr60298a003 
[22] Williams, L. L., Rubin, J. B., Edwards, H. W. "Calculation of Hansen Solubility Parameter Values for a Range of Pressure and Temperature Conditions, Including the Supercritical Fluid Region", Industrial \& Engineering Chemistry Research, 43(16), pp. 4967-4972, 2004.

https://doi.org/10.1021/ie0497543

[23] Williams, L. L. "Determination of Hansen Solubility Parameter Values for Carbon Dioxide", In: Hansen, C. M. (ed.) Hansen Solubility Parameters: A User's Handbook, 2nd ed., CRC Press, Boca Raton, FL, USA, 2007, pp. 177-201. https://doi.org/10.1201/9781420006834.ch10

[24] Anwar, S., Carroll, J. J. "Density $\left(\mathrm{kg} / \mathrm{m}^{3}\right)$ of Carbon Dioxide as a Function of Temperature and Pressure", In: Carbon Dioxide Thermodynamic Properties Handbook, 1st ed., Wiley-Scrivener, Hoboken, NJ, USA, 2011, pp. 9-148.

https://doi.org/10.1002/9781118065693.ch5
[25] Pöhler, H., Kiran, E. "Volumetric Properties of Carbon Dioxide + Ethanol at High Pressures", Journal of Chemical \& Engineering Data, 42(2), pp. 384-388, 1997. https://doi.org/10.1021/je9602982

[26] Stefanis, E., Panayiotou, C. "Prediction of Hansen Solubility Parameters with a New Group-Contribution Method", International Journal of Thermophysics, 29(2), pp. 568-585, 2008. https://doi.org/10.1007/s10765-008-0415-z

[27 Louwerse, M. J., Maldonado, A., Rousseau, S., MoreauMasselon, C., Roux, B., Rothenberg, G. "Revisiting Hansen Solubility Parameters by Including Thermodynamics", ChemPhysChem, 18(21), pp. 2999-3006, 2017. https://doi.org/10.1002/cphc.201700408 